\title{
The Revenge of Human Heroes in Old Tale Retold
}

\author{
Xi Weixuan \\ School of Liberal Arts, Nanjing University, Jiangsu, China, 210023 \\ Keywords: Lu Xun, Old Tale Retold, Heroes, Revenge \\ Abstract: Lu Xun put the legendary heroes or sages from altar to the real world of mankind \\ to provide them with the possibility of revenge. Besides Mei Jianchi and Black Man in \\ Forging the Swords, Lu Xun also entrusted the faith of revenge on the other characters.
}

\section{Introduction}

Lu Xun gave modern environment to ancient legends in Old Tale Retold, In the scene of ancient and modern replacement, the ancient sages or mythological heroes faded away their divinity quietly and then became the heroes of human world, such as Zhuang $\mathrm{Zi}, \mathrm{Da} \mathrm{Yu}$, Hou Yi and so on , they also came back from fairy tales to reality.

"At the end of Ming Dynasty, Wang Siren might have said that: ' Hui Ji is a land of revenge not a place of dirt. ' This is very glorious for Shao Xing people, and I also would like to hear or quote that. " It can be seen as an outpouring of thoughts and revenge in Concession Kiosk Essays·Nu Diao. The Forging the Swords is undoubtedly one of the most representative works of Lu Xun's revenge thought. But in Old Tale Retold, Lu Xun is not only entrusted with his revenge ideal to the Mei Jianchi and Yan Zhiao, but also to the other protagonists. Readers can also see the same reason between the protagonists and Lu Xun's idea of revenge.

\section{The Back of Heroes on Earth}

The protagonists in the Old Tale Retold, whether the heroes in the legend or the sages in the book, was drawn back to the real world by Lu Xun before their act of revenge. In Lu Xun's works, those heroes who were full of divinity were confined to some kind of quandary. Hou Yi was no longer the image of the martial arts in Huai Nanzi, but came into a mundane life of mediocrity. The betrayal of his student and the abandonment of his wife Chang'e deepened Hou Yi's loneliness and misfortune in the human world.

In order to pulled the mythical heroes down the altar and brought them down from deity to personality, in addition to giving heroes a secular material predicament or spiritual loneliness, Lu Xun also created a sense of the samsara of destiny to make the mythical characters who had gone beyond the dead were faced with the test of life as much as the mortals through the echo from beginning to end. For example, Mending Heaven began with"Nu Wa suddenly woke up...There was a shining sun in the blood-red clouds of the sky, like a flowing golden ball in the rarefied lava; on the other side was a cold, white moon, as cold as pig iron."But at the end of the book, Nu Wa spat out her"last breath"with the"same shining sun and the cold white moon". There was a dead silence all around. From waking up in a dream to being unable to breathe, and then into a dead silence, the 
author's arrangement in this plot was full of the shadow of Buddhist reincarnation. And the same description of the environment of the whole text, just as Lu Xun used in Hometown. They were building a primitive, desolate and absurd world, but also implied that even $\mathrm{Nu} \mathrm{Wa}$, the creator of the world, can not transcend the plight of death from the human world.

After returning to the world, the heroes or sages in Old Tale Retold seem to have retained the name of heroes or saints just because of their connection with the original text. After Lu Xun's secularization, they have become just like ordinary people, with a secular human nature and defects. In the context of modernization, in the changing scene of ancient and modern times, from the lofty altar to the ordinary earth, Lu Xun didn't rashly disconnect them from the old text in dealing with the relationship between these characters and the original text. On the contrary, he selected, spliced and synthesized different versions of the same story besides retaining the link between the novel and the original text, so that the original characters which were only in one version became plentiful, but also make the development of the story intriguing.

For example, the story of Chang'e flight to the moon was found in Huainan Zi, while the story of Feng Meng shot Hou Yi was found in Zhuang Zi· Li Lou. Lu Xun combined the stories related to Hou Yi in different historical texts into a new plot in The Flight to the Moon, which not only maintained the connection with the original text, but also generated a new narrative logic. This narrative reinforced Hou Yi's dilemma of losing momentum and paved the way for the last explosive revenge of the character.

\section{Revenge Choice beyond Forging the Swords}

By pulling heroes or saints back into the human world and putting them in a hard situation, Lu Xun arranged a more reasonable and acceptable premise for the revenge of the following characters. Of the eight stories in Old Tale Retold, Forging the Swords is the most typical novel with a theme of revenge. Lu Xun also showed his revenge ideals in the other stories besides Forging the Swords.

"Revenge" was not a simple monistic concept in $\mathrm{Lu}$ Xun's works, but a complex spiritual connotation. Revolt and revenge were not two separate concepts in Lu Xun's works, but were interchangeable in the text. Lu Xun advocated revenge in Moluoshili. This kind of revenge transcended personal grudges and pointed the revolt of oppressed person. As Lu Xun wrote in his letter to Xu Guangping, "Did you fight for the light?... But my revolt is nothing but a disturbance to the darkness.” Lu Xun wrote the irrevocable "desperate” situation in Wild Grass, which aroused "my" re-understanding of life, the meaning of life existed in the resistance to this "despair". Therefore, the practice of revenge can not be separated from the act of resistance, and the struggle of despair should be linked with the act of revenge.

The plot of Hou Yi shot the moon after Chang'e ran to it was a manifestation of revenge at the despereate situation, but Hou Yi's object of revenge was not Chang'e. Before his anger, Hou Yi thought of the beautiful scenery in the moon which he had heard in his childhood. The ethereal hope contrasted strongly with the despair of reality, so Hou Yi shot the moon, not to retaliate against Chang'e, who had stolen immortals, but to avenge the difficult situation in which he lived, he tried to shoot the moon in order to break away from human suffering and despair. However, Hou Yi advanced three steps, the moon retreated three steps; he retreated three steps, the moon moved three steps forward. Shooting the moon would not do anything but gave the moon a greater glow of harmony. Hou Yi's revenge finally slid to a windy state, and the hero fell deeper into solitude and despair. Facing the despair of the human world, Hou Yi chose to continue to pursue an ethereal hope, as if still not giving up fighting against the dark and hopeless human world.It reflected the irreconcilable contradiction between heroes and reality. 
When the characters had the possibility of revenge, whether to chose revenge or revolt, or how much to invest in revenge, was also a point worth discussing in Old Tale Retold.These choices were related both to the original legends and to the author's own considerations.In Out of Customs,Lao Tzu from the Taoist ancestor,the legend of the fairy who was riding cattle, restored to a person.He went west to Tong Guan in order to escape the possible persecution of Confucius.In terms of the degree of embarrassment in reality, it was difficult for readers to compare Lao Tzu's suffering with Hou Yi's.But what can be sure was that Lao Tzu who returned to the human world and struggled in an awkward world had the reasons for resisting and avenging the Confucianists represented by Confucius and the mediocrity represented by Guan Yinxi.However, in the face of Confucius, Lao Tzu chose to "step back with flexibility"; in the face of such secular mediocrity as Guan Yinxi, Lao Tzu chanted“The way of saints is indisputable”, After writing the handout, Lao Tzu thought, "In order to get out of the customs, I think it's over."Escape, indisputable and perfunctory were Lao Tzu's choice in the face of the world.Gave up revenge when he can choose revenge, this choice designed by Lu Xun for Lao Tzu not only accepted the influence of Taoist ideas, but also revealed to the reader another choice when mortal heroes or saints were faced with the plight of the world.But there was no room in the world for Lao Tzu to back down.It just a geographical escape, not a spiritual escape.Even though Lao Tzu had temporarily escaped the control of Confucianism and mediocrity, he could not escape the troubles of survival.Lu Xun's sarcastic style shows the awkward situation of the traditional intellectuals.

\section{Revenge and Hero Reconstruction in Forging the Swords}

Forging the Swords was one of the works that can best express Lu Xun's thought of revenge, it mainly came from strange novels of Sou Shen Ji and Different Biography of Wei-Jin Dynasty. In Lu Xun's writings, Mei Jianchi went from a thin image to a vibrant and dynamic one, it also showed a state of indecision.

The author made Mei Jianchi more closer to a person's image without weakening the legendary color. "I do analyze people all the time,I was more ruthless in dissecting myself ", Lu Xun wrote in Written Behind the Grave. As for Yan Zhiao in Forging the Swords,Lu Xun cast many of his own shadows and thoughts.In terms of appearance, he was born as a "black man "with "a general look of phosphorous fire”. He wore black clothes and black hair.He looked like a thin black beggar.It coincided with Xu Guangping's recollection of Lu Xun, who taught in female normal University. In terms of spirit,Yan Zhiao refused to be called "righteous man",and said that "justice and compassion"were all capital of ghost debt. "There were so much harm of others in my soul,I hate myself”, he said.It is consistent with Lu Xun's spirit of revenge and the reflection and suicide consciousness of the spirit of the new era.In this way, the Yan Zhiao also changed from the image of "guest" in the original text to the reflection of Lu Xun's life and spirit, and returned to the world from the historical text.

Mei Jianchi's revenge in Forging the Swords can still be understood as a revenge for blood, while the revenge of the Yan Zhiao transcended the pattern of revenge for relatives and friends. It is more like singing about the spirit of revolt, so as to kill the king to realize revenge on the ruler.In the novel, Lu Xun replaced the concepts of “rebellion” and "revenge”once again.Mei Jianchi avenged his father with the help of Yan Zhiao,and Yan Zhiao achieved resistance to the ruler with the help of Mei Jianchi.The spiritual core of the two was interlinked in the text.Revenge was to resist the oppression of the king, and then the resistance leaded to the idea of revenge.However,the songs in style of Chu Ci rendered a solemn atmosphere.It made a sad contrast with the funny scenes in the end of the text.How can the heroes of human world escape the secular audience and the mediocre crowd? The sages and the sublime of vengeance were cleaned up,the kind of vengeance 
like Forging the Swords is still inevitable in the nothingness of the world.

\section{Conclusion}

From Nu Wa to Hou Yi,from Hou Yi to Mei Jianchi,Yan Zhiao and to Lao Tzu,Lu Xun took off the mythical veils of the heroes and sages, and pulled them to human world in Old Tale Retold.This kind of arrangement was like what he emphasized the identity of the crucified Lord's son was the son of man not the son of God in Revenge(II).Lu Xun reconstructed the images of heroes and saints in these traditional texts in his own way.Through his Nu Wa, Hou Yi,Yan Zhiao and other characters, we can easily see Lu Xun's gaze and reflection on the cruel and absurd real world, as well as the pursuit and doubt of revenge ideal after staring and reflecting.

\section{References}

[1] Lu Xun, Concession Kiosk Essays·Nu Diao[A],Lu Xun's Complete Works(Volume six)[C], Beijing: People's Literature Publishing House,1981.

[2] Lu Xun,Old Tale Retold[M],Tianjin: Tianjin people's Publishing House,2015.

[3] Lu Xun, Two Books. Two Four[A], Lu Xun's Complete Works(Volume eleven)[C], Beijing: People's Literature Publishing House, 1981.

[4] Wang Hui,The philosophy of Life against despair and the spiritual characteristics of Lu Xun's novels[J]. Research Trends of Lu Xun, 1988(09).

[5] Yang Cheng,On the Portrayal of the Character of "Hero" and the Analysis of Human Nature by Lu Xun[J]. Journal of Hubei University for Nationalities (Philosophy and Social Sciences Edition),2016(01).

[6] Lu Xun,Written Behind the Grave[A],Lu Xun's Complete Works(Volume one)[C], BeiJing: People's Literature Publishing House, 1981.

[7] Huang Yihong,Revolt Revenge Revolution--An Interpretation of Lu Xun's novel Forging the Sword[J], Journal of Tsinghua university,2013(S1). 